\section{STRESS PASIEN DENGAN ULKUS KAKI DIABETIKUM DI AL HIJRAH WOUND CARE CENTER JOMBANG}

\section{The Study of Stress Patients With Diabetic Ulcers In Al Hijrah Wound Care Center}

\author{
Fahruddin Kurdi ${ }^{1}$, Anja Hesnia Kholis ${ }^{2}$, Nurul Hidayah ${ }^{2}$, Maya Fitriasari ${ }^{3}$
}

1. Fakultas Keperawatan Universitas Jember

2. Prodi Pendidikan Ners STIKES Pemkab Jombang

3. Pediatric Nurse RSIA Muslimat Jombang

\section{Riwayat artikel}

Diajukan: 10 Maret 2020

Diterima: 28 Maret 2020

Penulis Korespondensi:

- Anja Hesnia Kholis

- STIKES Pemkab Jombang hesniaanja@gmail.com

\section{Kata Kunci:}

Diabetes, Ulkus Kaki, Stress, Luka

\begin{abstract}
Abstrak
Pendahuluan: Ulkus kaki diabetikum merupakan salah satu komplikasi dari dibetes mellitus. Komplikasi ini dapat menyebabkan gangguan psikologis berupa stress bagi penderita. Semakin tinggi derajat ulkus kaki diabetikum maka akan meningkatkan stress pada penderita. Pada tahap ini penderita harus dapat beradaptasi dengan kondisi yang dialaminya dengan cara mengurangi stress secara mandiri, selain itu suport sistem dari keluarga sangat diperlukan untuk membantu mengurangi stress dan beban psikologis. Tujuan penelitian ini mengetahui bagaimana stress yang di alami penderita ulkus kaki diabetikum. Metode: Penelitian ini merupakan penelitian kualitatif dengan pendekatan fenomenologi. Partisipan merupakan penderita ulkus kaki diabetikum yang melakukan perawatan luka di Al hijrah wound care center, serta keluarga inti sebagai informan tambahan. Data diambil dengan wawancara secara mendalam, observasi.

Hasil penelitian diperoleh dari 2 partisipan bahwa stress akibat ulkus diabetikum adalah suatu kondisi yang mempunyai pengaruh terhadap kondisi fisik maupun psikis dan menyebabkan partisipan mengalami stress antara lain: gangguan citra tubuh, kesulitan bergerak, takut di amputasi dan keterbatasan biaya perawatan. Diskusi: Upaya utama untuk mengurangi stress adalah dengan mendekatkan diri pada tuhan, sholat, membaca Al-Quran, zikir dan mencari pertolongan petugas kesehatan terdekat dengan harapan stress yang timbul dapat di kurangi secara mandiri dan tidak menimbulkan komplikasi yang labih buruk. Diharapkan penelitian selanjutnya mengkaji lebih dalam tentang stress yang dialami pasien dengan ulkus kaki diabetikum.
\end{abstract}

\begin{abstract}
Introduction Diabetic foot ulcer is a complication of mellitus. The complication can cause psychological problems that cause stress for patient. The severity of diabetic foot ulcer will increase stress in patients. To deal with stress that needs to be overcome by reducing stress independently, besides the support system of the family is needed to help reduce stress and psychological burden. The purpose of this research is to explore how stress is experienced by diabetic foot ulcer patient. Methods: This research is a qualitative research with phenomenology approach. Participants were diabetic ulcer who come for wound care treatments at Al Hijrah wound care center, as well as the nuclear family as additional informants. Data is taken with a thorough interview, observation.

The results obtained from two participants that stress due to diabetic ulcers is a condition related to physical and psychological conditions that cause participants to increase stress, such as: body image disorders, immobility, fear to amputation and cost difficulties. Discussion: The main effort to reduce stress is pray, read the Al Quran, dzikr and ask for help to health services in the hope that the stress can reduced independently and does not cause worse complications. It is hoped that further research will examine more deeply the stress experienced by patients with diabetic ulcers.
\end{abstract}

\section{PENDAHULUAN}

Diabetes mellitus merupakan penyakit metabolik kronis yang dapat menimbulkan stres dan rasa putus asa bagi penderita untuk mencapai kesembuhannya (Ndraha, 2014).. Nevid 
Jeffrey S, Rathus Spencer A, \& Greene Beverly (2005) menggambarkan kecemasan sebagai suatu keadaan emosional yang mempunyai ciri keterangsangan fisiologis, perasaan tegang yang tidak menyenangkan, dan kekhawatiran bahwa sesuatu yang buruk akan terjadi. Reaksi stress yang timbul dapat berupa kemarahan, kecemasan yang nantinya dapat membahayakan kondisi fisik serta psikologis

International Diabetes Federation mencatat jumlah penderita DM sebanyak 425 juta orang pada tahun 2018. Estimasi oleh badan tersebut akan meningkat pada tahun 2045 sejumlah 629 juta orang di dunia (IDF, 2018). Pada tahun 2017 prevalensi penderita diabetes melitus di Kabupaten Jombang pada layanan rawat jalan sejumlah 6,917 orang dan pada rawat inap sejumlah 913 orang, sampai saat ini penyakit diabetes melitus merupakan salah satu penyakit dengan jumlah kasus terbanyak di Kabupaten Jombang (DINKES JOMBANG, 2018). Penyakit ini dapat menimbulkan komplikasi akut maupun kronik. Salah satu komplikasi kronik yang sering muncul adalah ulkus kaki diabetikum (Waspadji, 2009).

Stress pada pasien ulkus kaki diabetikum dapat di sebabkan karena ketakutan terjadinya amputasi. Untuk mencegah amputasi, pasien harus melakukan perawatan luka dengan tepat. Perawatan ulkus kaki diabetikum membutuhkan biaya yang tidak sedikit, hal ini berdampak pada status ekonomi bagi penderitanya yang juga merupakan salah satu stressor pada pasien. Selain itu, ulkus kaki diabetikum juga berdampak pada perubahan sosial karena penderita mengalami kondisi yang menyebabkan rasa sakit, gangguan aktifitas dan bau tidak sedap (Vileikyte, et al, 2009).

\section{METODE}

kualititif dengan pendekatan

Desain penelitian menggunakan fenomenologi. Partisipan pada penelitian ini adalah pasien dengan diabetes mellitus dengan komplikasi ulkus kaki diabetikum yang ditentukan sesuai kriteria penelitian, serta keluarga penderita inti sebagai informan tambahan dan triangulasi. Waktu pengambilan informasi dilakukan sesuai dengan kemauan dan permintaan partisipan.

Pengumpulan data menggunakan observasi, wawancara mendalam (in dept interview) dengan model semi structure. Alat bantu penelitian yang digunakan adalah perekam suara. Analisa data menggunakan tahapan data reduction, data display, dan conclusion/ verification. Keabsahan data menggunakan triangulasi sumber.

\section{HASIL DAN PEMBAHASAN}

Karakteristik partisipan dalam penelitian ini berjenis kelamin perempuan sebanyak 2 orang, partisipan pertama sudah sakit diabetes mellitus sejak lima tahun dan partisipan berikutnya tiga tahun yang lalu. Profesi sebelum sakit partisipan pertama sebagai pedagang bakso dan partisipan pertama sebagai petani.

\section{Stress Akibat Gangguan Citra Tubuh}

Penderita ulkus kaki diabetikum umumnya merasa malu, terasing, kurang puas dengan kondisi tubuhnya yang membuatnya merasa kurang percaya diri dan timbulnya rasa putus asa. Hal ini dikarenakan penderita kurang mampu menerima perubahan yang terjadi di tubuhnya. Perubahan tersebut meliputi perubahan dalam penampilan, strusktur, dan fungsi tubuh penderita sehingga akan mempengaruhi citra tubuh seseorang (Lestari, Warjiman, \& Barewe, 2017).

Kebanyakan partisipan yang sakit diabetes mellitus dengan ulkus kaki diabetikum mengalami stress akibat kondisi yang semakin memburuk dan terjadinya perubahan fisik, selain itu partisipan juga merasa tidak puas dengan keadaan kaki yang tidak dapat normal seperti dulu. Partisipan mengalami rasa malu terhadap kaki yang luka,Hal ini sama dengan apa yang di ungkapkan Ny.L selaku partisipan 1 (P1) sebagai berikut:

"nggeh nang jero ati iku mboten purun medal wedi di omongno uwong ngunu lo". (Pl) 
Kata-kata tersebut dapat diartikan dalam

Bahasa Indonesia sebagai berikut :

"ya di dalam hati nggak mau keluar, takut di omongin orang gitu lo"..(Pl)

Hal yang senada juga diungkapkan oleh Ny.K selaku partisipan 2 (P2) sebagai berikut :

"dadine isin nek ketemu uwong, borok e iki lo mas seng garai isin "(P2)

Kata-kata tersebut dapat diartikan dalam

Bahasa Indonesia sebagai berikut:

"jadinya malu ketemu orang,

lukanya ini lo mas yang buat malu”.(P2)

Pernyataan yang tidak jauh berbeda juga diungkapkan oleh keluarga partisipan 1 dan $2(\mathrm{~K} 1 / \mathrm{K} 2)$ berikut adalah pernyataannya:

"mboten purun sanjange wedi di paido wong wong" (K1)

Pernyataan di atas dapat di artikan dalam

Bahasa Indonesia sebagai berikut:

"nggak mau katanya takut di ejek orang".(K1)

Dan berikut adalah pernyataan yang di ungkapkan oleh keluarga partisipan kedua yaitu keluarga Ny.K (P2) :

"cuma pikirane mak ne lare lare niku mawon sing ajrih". (K2)

Pernyataan di atas dapat di artikan dalam

Bahasa Indonesia sebagai berikut:

"pikirannya istri saya aja yang

ketakutan secara berlebihan”.(K2)

Dari pernyataan yang di sampaikan oleh partisipan, kebanyakan orang yang mengalami ulkus kaki diabetikum merasa malu dan takut untuk berinteraksi dengan orang lain. Menurut mereka dengan kondisi fisik yang sekarang, orang lain akan memandang rendah dan menjadikan mereka bahan ejekan karena perubahan bentuk fisik yang terjadi, selain itu lebih memilih di dalam rumah dan tidak berinteraksi dengan orang lain adalah hal yang di lakukan sampai sekarang.

Citra tubuh yang positif adalah kondisi dimana seseorang dapat beradaptasi terhadap perubahan tubuh, struktur serta fisiologis tubuh, yang tidak mengekspresikan perasaan tidak berdaya, tidak putus asa, mampu mengendalikan diri dalam tekanan keadaan.

Kozier, et al (2010) memaparkan bahwa citra tubuh individu berkembang sebagai dari sikap dan respon terhadap keadaan tubuh, sebagian lagi dari eksplorasi individu terhadap tubuhnya sendiri. Banyak faktor yang berpengaruh, salah satunya adalah berasal dari sumber internal yaitu rasa percaya diri dan nilai diri. Semakin besar sumber internal yang dimiliki seseorang, maka dampak pada konsep diri akan semakin positif.

Citra tubuh yang negatif merupakan keadaan dimana seseorang dapat asertif terhadap perubahan penampilan, anatomis atau fisiologis tubuh. Dari hasil penelitian didapatkan bahwa penderita merasa malu, merasa asing, tidak puas terhadap kondisi tubuh yang dialami. Keadaan ini membuat penderita merasa kurang percaya diri dan merasa putus asa. Hal ini dimungkinkan karena penderita tidak mampu beradaptasi dan menerima perubahan yang terjadi pada tubuh karena ulkus kaki. Saat berinteraksi dengan orang lain penderita merasa berbeda dan merasa tidak normal pada tubuhnya yang menimbulkan rasa malu, tidak percaya diri dan putus asa. Tekanan seperti ini menimbulkan perasaan dan penerimaan diri yang negatif yang mempengaruhi citra tubuh seseorang. Penderita akan merasa stress secara fisik maupun psikologis. Beberapa dampak fisik yang muncul yaitu pada sistem imun yang menurun dan memperlambat proses penyembuhan luka. Secara psikologis pasien merasa putus asa, tidak kooperatif dengan terapi pengobatan yang diberikan sehingga akan memperpanjang masa pengobatan.

$$
\text { Kozier, et al (2010) }
$$

mengemukakan bahwa seseorang yang memiliki citra tubuh negatif cenderung terlalu mengkhawatirkan penyakit dan abai terhadap pola aktivitas, pola istirahat dan asupan gizi. Individu dengan gangguan citra tubuh seringkali akan menyembunyikan bagian tubuh yang mengalami gangguan/penyakit, tidak melihat atau menyentuh bagian yang 
strukturnya telah berubah. Beberapa individu dapat mengekspresikan perasaan tidak berdaya, kerapuhan dan putus asa.

\section{Stress karena kesulitan bergerak}

Ulkus kaki diabetikum dapat menyebabkan penurunan mobilitas yang berpengaruh terhadap kemampuan pasien dalam melakukan gerakan sederhana, aktifitas harian (activity dayly living). Selain itu juga penurunan mobilitas disebabkan karena nyeri pada ulkus penderita (Ribu \& Wahl, 2004).

Perluasan area luka partisipan diabetess mellitus dengan ulkus kaki diabetikum menyebabkan kesulitan dalam bergerak untuk melakukan aktivitas sehari hari, mereka menjadi bergantung pada orang lain karena tidak bias melakukan kegiatan secara mandiri. Sehingga stress meningkat akibat keterbatasan dalam mobilitas fisik yang di alami saat ini.

Partisipan mengalami kesulitan dalam bergerak karena luka yang ada pada kaki. Hal ini sama dengan apa yang di ungkapkan Ny.L selaku partisipan 1 (P1) sebagai berikut:

"aku nang jeding ae dituntun karo anakku” (P1)

Pernyataan di atas dapat di artikan dalam

Bahasa Indonesia sebagai berikut:

"saya ke kamar mandi saja di bantu

sama anak saya".(P1)

Pernyataan diatas juga hampir sama dengan apa yang diungkapkan oleh partisipan kedua yaitu Ny.K (P2) berikut ini :

\section{"mlampah damel blonjo niku nggeh} sakit sikil kulo niki”. (P2)

Pernyataan di atas dapat di artikan dalam

Bahasa Indonesia sebagai berikut:

"jalan untuk belanja itu saja sakit

sekali kaki saya ini”.(P2)

Keluarga partisipan 1 dan 2 (K1/K2)juga mendukung pernyataan yangdi berikan oleh partisipan 1 dan 2 (P1 dan P2) bahwa partisipan yang mengalami ulkus kaki diabetikum kesulitan dalam bergerak. dengan pernyataan sebagai berikut:

"nek kepingin ten jading nggeh kulo bopong'.(K1)
Pernyataan di atas dapat di artikan dalam

Bahasa Indonesia sebagai berikut:

"jika ingin ke kamar mandi gitu saya yang gendong”. (K1)

Berikut adalah pernyataan yang di ungkapkan oleh keluarga partisipan kedua yaitu keluarga Ny.K (P2) :

$$
\begin{aligned}
& \text { "mlampah paling yo nang } \\
& \text { pawon".(K2) }
\end{aligned}
$$

Pernyataan di atas dapat di artikan dalam Bahasa Indonesia sebagai berikut:

" mungkin berjalan hanya ke dapur saja”.(K2)

Mobilitas terstruktur dan aktivitas fisik sangat efektif untuk meningkatkan sensitifitas hormon insulin, sehingga glukosa lebih terkontrol (Bweir et al., 2009). Rismayanthi (2010) menyatakan bahwa aktifitas dapat meningkatkan daya kerja hormon insulin dan kebutuhan insulin dapat menurun. Aktifitas seperti olah raga pada DM sangat penting untuk dilakukan, dibantu dengan diet dan obat penurun kadar glukosa akan mencegah resiko hipoglikemia atau hiperglikemia. Partisipan dalam melakukan aktivitas sangat kesulitan karena merasakan nyeri pada kaki. Rasa nyeri yang timbul saat berjalan dapat dikurangi dengan menggunakan alas kaki khusus penderita DM. Hal ini di dukung penelitian (Bus, Haspels, \& Busch Westbroek, 2011), penelitiannya menunjukkan bahwa pemakaian alas sepatu sangat efektif dan efisien untuk mengurangi tekanan pada kaki diabetik. Pasien dengan ulkus kaki diabetik dapat melakukan aktifitas terstruktur seperti olahraga ringan untuk menjaga kestabilan kadar glukosa. Selain itu hal tersebut dapat membantu menjaga sensitivitas insulin sehingga glukosa darah lebih terkontrol.

\section{Stress Akibat Amputasi}

Semakin tinggi derajat ulkus semakin tinggi resiko amputasi (Muliawan dkk, 2005). Komplikasi ini merupakan masalah yang meningkat dan merupakan penyebab utama amputasi dan kematian pada pasien diabetes militus (Desalu et al., 2011). Jika amputasi merupakan pilihan tatalaksana untuk kaki 
diabetik, bukan hanya estetika yang hilang, melainkan rasa percaya diri juga bisa hilang sebagai konsekuensi dari amputasi. Ancaman amputasi mampu memicu stress pada pasien ulkus kaki diabetikum (Kurdi, 2019).

Salah satu cara untuk menanggulangi perluasan area luka yaitu dengan membuang jaringan-jaringan mati dan memotong bagian yang di rasa memperparah infeksi, amputasi adalah hal yang paling di takutkan oleh partisipan, ketika mengetahui akan di lakukannya amputasi hal pertama yang di rasakan partisipan yaitu jantung berdegup lebih cepat dari biasanya, merasa lemas dan khawatir akan kondisinya.

Hasil wawancara menunjukkan bahwa kedua partisipan mengalami stress saat ulkus kaki diabetikum yang semakin parah dan di sarankan untuk mengamputasi bagian yang mengalami nekrosis. Berikut ini ungkapan masingmasing partisipan :

"di obo kongkon operasi ngunu

awakku langsung luwemes saking

mikire". (sambil mengelus dada) (P1)

Pernyataan di atas dapat di artikan dalam Bahasa Indonesia sebagai berikut:

"ketika di sarankan di operasi

badan saya langsung terasa lemas terlalu memikirkan".(P1)

Pernyataan diatas juga hampir sama dengan apa yang diungkapkan oleh partisipan kedua yaitu Ny.K (P2) berikut ini :

"Pas ngerti nek kate di potong iku atiku iso mak tratap-tratap”.'(sambil memegang dada kiri) (P2)

Pernyataan di atas dapat di artikan dalam

Bahasa Indonesia sebagai berikut:

"waktu mengetahui akan di potong

$$
\text { jantung saya berdegup }
$$

kencang".(P2)

Pernyataan partisipan tersebut didukung oleh pernyataan dari kedua keluarga partisipan $(\mathrm{K} 1 / \mathrm{K} 2)$ bahwa partisipan yang mengalami ulkus diabetikum merasakan nyeri pada lukanya. Berikut pernyataan dari masing-masing pernyataan dari keluarga partisipan: "mboten karuan ngunu paling pas

krungu di kongkon operasi”.,(K1)

Pernyataan di atas dapat di artikan dalam

Bahasa Indonesia sebagai berikut:

"tidak karuan begitu ketika

mendengar akan di operasi". (Kl)

Pernyataan diatas juga hampir sama dengan apa yang diungkapkan oleh keluarga partisipan pertama berikut ini adalah pernyataan dari keluuarga partisipan kedua (K2):

"eroh nek kate di puthol niku mular

ae tambahan." (sambil tersenyum)

(K2)

Pernyataan di atas dapat di artikan dalam

Bahasa Indonesia sebagai berikut:

"saat mengetahui akan di potong

malah menangis saja".(sambil tersenyum)

\section{Stress Sebagai akibat dari Keterbatasan Biaya}

Berdasarkan

penelitian

sebelumnya, ditemukan terkait status sosial ekonomi, (pendapatan, pendidikan) berpengaruh terhadap kejadian penyakit diabetes melitus (Khrishnan et al., 2010). Penderita dengan komplikasi makrovaskular atau mikrovaskular memiliki biaya tiga kali lebih tinggi dibandingkan penderita diabetes tanpa komplikasi (Henriksson, et al, 2000).

Akibat perawatan yang lama dan biaya yang tidak murah menjadi salah satu penyebab stress muncul, di tambah lagi apabila ekonomi keluarga dalam golongan rendah, menrut partisipan pemenuhan untuk biaya hidup sehari hari sudah sulit di tambah dengan biaya yang harus di keluarkan oleh keluarga akan menjadikan beban pikiran bagi partisipan.

Pada saat dilakukan wawancara kedua partisipan mengatakan merasa stress karena terbatasnya biaya untuk perawatan kakinya. Berikut pernyataan partisipan:

"mbuh polahe piye anakku gawe

nambakno aku”.(sambil senyum) (P1)

Pernyataan di atas dapat di artikan dalam Bahasa Indonesia sebagai berikut: 
"tidak tahu tahu bagaimana caranya anak saya untuk berobatin saya".

(P1)

Pernyataan diatas juga hampir sama dengan apa yang diungkapkan oleh partisipan kedua yaitu Ny.K (P2) berikut ini :

"mikir talah wong di gawe butuhan bendino ae soro ne koyok ngene". (sambil tertawa)(P2)

Pernyataan di atas dapat di artikan dalam Bahasa Indonesia sebagai berikut:

"ya mikir orag buat kebutuhan sehari hari aja sulit”. (P2)

Pernyataan partisipan tersebut didukung oleh pernyataan dari kedua keluarga partisipan (K1/K2) bahwa partisipan yang mengalami ulkus diabetikum merasakan nyeri pada lukanya. Berikut pernyataan dari masing-masing pernyataan dari keluarga partisipan:

"emak niku wes tak omongi padahal ojo mikir mbayar". (sambil melihat kearah prtisipan 1)(K1)

Pernyataan di atas dapat di artikan dalam Bahasa Indonesia sebagai berikut:

"ibu itu sudah saya saya kasih tahu, jangan mikirin biaya". (K1)

Pernyataan diatas juga hampir sama dengan apa yang diungkapkan oleh keluarga partisipan pertama berikut ini adalah pernyataan dari keluuarga partisipan kedua (K2):

"nek masalah duwek kenek di golek

I seng penting waras sek".(K2)

Pernyataan di atas dapat di artikan dalam

Bahasa Indonesia sebagai berikut:

"kalo masalah uang bias di cari yang penting sembuh dulu". (K2)

\section{Upaya Melakukan Ritual Atau Perilaku} Tertentu Agar Stress Berkurang

Pada penderita ulkus diabetikum cenderung untuk lebih meningkatkan spiritualnya serta lebih taat kepada sang pencipta dengan cara selalu berusaha mendekatkan diri kepada Tuhan. Sholat serta membaca Al-Quran banyak sekali manfaatnya salah satunya adalah sebagai syifa (obat) sehingga masalah stress yang di alami dapat di kurangi (Nugraheni dkk., 2018)
Stress yang semakin meningkat akibat penyakit yang di derita akan berdampak buruk apabila tidak di tangani sesegera mungkin. Hal yang sering di lakukan yaitu dengan melaksanakan sholat dan membaca ayat-ayat suci AlQuran, dan kegiatan ini dinilai sangat ampuh untuk mengurangi stress.

Dari uraian diatas bahwa stress akibat dari masalah kesehatan dapat ditangani dengan melakukan ibadah sholat dan membaca Al-Quran, seperti yang dikatakan ke 2 partisipan dan Trianggulasi adalah :

"sholat kulo mas ten ndukur kasur niku, lah kate piye neh, sak mantune sholat niku rodok ondan mas".(P1)

Pernyataan di atas dapat di artikan dalam Bahasa Indonesia sebagai berikut:

"saya sholat di atas tempat tidur, mau bagaimana lagi, setelah sholat sedikit tenang".(P1)

Pernyataan diatas juga hampir sama dengan apa yang diungkapkan oleh Ny.K (P2) berikut ini :

"nggeh moco sak isone mas, jenenge wong kepikiran, istigfar iku gak pedot".(P2)

Pernyataan di atas dapat di artikan dalam Bahasa Indonesia sebagai berikut:

"membaca sebisa saya mas, namanya orang sedang stress, istigfar tidak pernah putus". (P2)

Perilaku yang dapat dilakukan agar stress akibat ulkus diabetikum bisa berkurang adalah dengan cara sholat fardhu dan membaca Al-Qur'an serta zikir membuktikan bisa mengurangi stress akibat ulkus diabetikum tersebut. Hal ini di buktikan juga dari pernyataan kedua keluarga partisipan (K1/K2) sebagai berikut:

"sholat iku karo nangis tapi nek bar sholat ngoteniko mpun tenang ".( tersenyum sambil menutup mulut)(K1)

Pernyataan di atas dapat di artikan dalam Bahasa Indonesia sebagai berikut: "sholat itu sambal nangis tapi setelah sholat gitu sudah tenang." (K1) 
Pernyataan berikut merupakan peryataan dari keluarga partisipan kedua (K2) tentang penurunan stress dengan cara ibadah:

"moco istiqfar,surat al-ikhlas,annas pokok seng gampang gampang niku lo mas". ( sambil tertawa)(K2)

Pernyataan di atas dapat di artikan dalam Bahasa Indonesia sebagai berikut:

"baca istiqfar, surat a-ikhlas, an-nas pokoknya yang mudah-mudah gitu lo mas". (K2)

\section{Upaya Mengurangi Stress Dengan Cara Mencari Pertolongan Tenaga Kesehatan}

Salah satu cara yang di tempuh oleh penderita diabetes mellitus yang di sertai dengan ulkus diabetikum yaitu dengan cara mencari pertolongan tenaga kesehatan terdekat. Pendidikan kesehatan sangat penting dalam pengelolaan. Pendidikan kesehatan pencegahan primer harus diberikan kepada kelompok masyarakat resiko tinggi. Pendidikan kesehatan sekunder diberikan kepada kelompok pasien DM. Sedangkan pendidikan kesehatan untuk pencegahan tersier diberikan kepada pasien yang sudah mengidap DM dengan penyulit menahun. Penelitian dari Saydah dan Lochner (2010) ditemukan bahwa seseorang dengan tingkat pendidikan yang rendah mempunyai resiko kematian dua kali lipat akibat diabetes setelah dikontrol dengan umur, jenis kelamin, etnis, dan IMT.

Selama penelitian peneliti menemukan bahwa apabila terjadi stress pada partisipan, partisipan pasti mendatangi petugas kesehatan terdekat untuk memeriksakan kesehatannya, setelah mengetahui kondisi kesehatannya partisipan merasa lebih tenang. Pendidikan kesehatan tentang diet makanan yang harus di lakukan partisipan selalu diberikan petugas kesehatan yang memeriksa kesehatan partisipan, pemberian motivasi serta pendidikan diakui partisipan dapat menurunkan kekhawatiran tentang penyakitnya.
Dari penjelasan diatas terbukti bahwa stress akibat dari ulkus diabetikum dapat di kurangi dengan cara mencari pertolongan petugas kesehatan, seperti yang dikatakan ke 2 partisipan dan Trianggulasi di bawah ini yaitu:

"mboten kantuk nginum es trus mangan seng legi-legi kalih pak Nur".(Pl)

Pernyataan di atas dapat di artikan dalam Bahasa Indonesia sebagai berikut:

"di larang minum es dan makan yang manis manis sam pak Nur".(P1)

Pernyataan diatas juga hampir sama dengan apa yang diungkapkan oleh Ny.K (P2) berikut ini :

"ambek bu En yo di kandani gak oleh mangan opo, terus opo seng oleh di pangan".(sambil tersenyum) (P2)

Perilaku tertentu agar stress akibat ulkus diabetikum bisa berkurang adalah dengan mencari pertolongan petugas kesehatan terdekat membuktikan bahwasannya bisa mengurai stress akibat ulkus diabetikum tersebut. Hal ini di buktikan juga dari pernyataan kedua keluarga partisipan (K1/K2) sebagai berikut:

" di sanjangi pak nur pasal diet $e$ niku".(K1)

Pernyataan di atas dapat di artikan dalam Bahasa Indonesia sebagai berikut:

"di beri pengetahuan sama pak Nur tentang dietnya". (K1)

Pernyataan diatas juga hampir sama dengan apa yang diungkapkan oleh keluarga partisipan kedua (K2) seperti berikut ini:

"yo mangan legine iku kudu di pre eni”. (K2)

Pernyataan di atas dapat di artikan dalam Bahasa Indonesia sebagai berikut:

"ya makan manisnya harus di batasin”. (K2)

\section{KESIMPULAN}

Hasil dari penelitian di dapatkan bahwa kedua partisipan mengalami stress dan stress yang dialami berupa stress karena gangguan citra tubuh, stress karena kesulitan bergerak, stress akibat akan di lakukannya amputasi, stress karena 
keterbatasan biaya. Kegiatan wajib yang dilakukan yaitu dengan cara beribadah, serta berupaya melakukan kontrol rutin ke pelayanan atau petugas kesehatan terdekat.

Diharapkan hasil penelitian ini dapat dijadikan sebagai bahan masukan dalam memberikan asuhan keperawatan pada pasien dengan ulkus kaki diabetikum dan sebagai bahan informasi untuk menambah pengetahuan tentang manajemen stress akibat ulkus diabetikum sehingga menimbulkan komplikasi yang lebih berat.

\section{DAFTAR PUSTAKA}

Bus, S. A., Haspels, R., \& BuschWestbroek, T. E. (2011). Evaluation and optimization of therapeutic footwear for neuropathic diabetic foot patients using in-shoe plantar pressure analysis. Diabetes Care, 34(7), 1595- 1600. https://doi.org/10.2337/dc10- 2206

Bweir, S., Al-Jarrah, M., Almalty, A.-M., Maayah, M., Smirnova, I. V, Novikova, L., \& Stehno-Bittel, L. (2009). Resistance exercise training lowers HbAlc more than aerobic training in adults with type 2 diabetes. Diabetology \& Metabolic Syndrome, 1(1), 27. https://doi.org/10.1186/1758- 5996-1-27

Desalu, O., Salawu, FK., Jimoh, AK., Adekoya, AO., (2011). Diabetic foot care: Self reported knowledge and practice among patients attending three tertiary hospital in Nigeria. Ghana Medical Journal. Vol 45, No 2 (2011).

http://dx.doi.org/10.4314/gmj.v45i2. 68930

DINKES JOMBANG. (2018). Profil Kesehatan Tahun 2018. Jombang.

Fikri, M \& Nurdian, Y. (2019). Ulkus Tungkai pada Pasien Diabetes 1. Universitas Jember: Medicine Faculty

Henriksson, F. (2000), Direct medical cost patients with type 2 diabetes in Sweden. Journal of Internal Medicine. 248: $387-$ 396. Diakses: 25 Januari 2020.

IDF. (2018). IDF 2018 Statistics. Brussels, Belgium: IDF.
Kurdi, F., \& Priyanti, R. P. (2019). MANAJEMEN ULKUS KAKI DIABETIKUM: EFEKTIFITAS FOOT EXERCISE TERHADAP RISIKO DFU (DIABETIC FOOT ULCERS) PASIEN DIABETES MELLITUS DI AL HIJRAH WOUND CARE CENTER. Jurnal Ilmiah PANNMED (Pharmacist, Analyst, Nurse, Nutrition, Midwivery, Environment, Dentist), 14(2), 95-101.

Kozier, et al. (2010). Buku Ajar : Fundamental Keperawatan : Konsep, Proses \& Praktik Volume 2 (Edisi 7). Jakarta : EGC.

Khrishan S,Cozier Y.C, Rosenberg L, Palmer JR. (2010). Socioeconomic Status and Incidence of Type 2 Diabetes: Results From The Black Women's Health Study. American Journal of Epidemiology (Online) Vol 171, No. 5 Hlm. 564-570 ( http://aje.oxfordjournals.org diakses pada 25 Januari 2020).

Lestari, A.S., Warjiman, W., \& Barewe, A. (2017). Gambaran Konsep Diri Pada Pasien Luka Gangren Diabetik Di Poliklinik Kaki Diabetik. Jurnal Keperawatan Suaka Insan (JKSI), 1(1), 1-10. https: //journal. Stikessuaka insan.ac.id/index.php/jksi/article/vie $\mathrm{w} / 13$

Muliawan, M., Semadi, N., Yasa, K.P. (2007). Pola Kuman dan Korelasi Klinis Ulkus Kaki Diabetikum di RSUP Sanglah Denpasar. Tesis. Denpasar: Universitas Udayana.

Nevid, Jeffrey S., Spencer. A. Rathus, dan Greene, Beverly. (2005). Psikologi Abnormal. Terjemahan Tim Psikologi Universitas Indonesia. Edisi Kelima. Jilid 1. Jakarta: Penerbit Erlangga.

Ndraha, S. (2014). Diabetes Mellitus Tipe 2 dan Tatalaksana Terkini. Depertemen Penyakit Dalam Fakultas Kedokteran Univeritas Krida Wacana Jakarta. Vol (27). No (2).

Nugraheni, D., Mabruri, IM., \& Stanislaus, S. (2018). Efektivitas Membaca al-qur'an Untuk Menurunkan Stres. Jurnal Psikologi 
ilmiah. Volume 10, Nomor 01 http://journal.unnes.ac.id/nju/index.p hp/INTUISI DOAJ: 2541-2965

Ribu, L., \& Wahl, A. (2004). How patient diabetes who have foot and leg ulcer perceive the nursing care they receive.

http://www.internurse.com/cgibin/go .pl/library/article.cgi?uid $=26578$, diperoleh tanggal 3 Maret 2020

Rismayanthi, C. (2010). Terapi Insulin Sebagai Alternatif Pngobatan Bagi Penderita Diabetes. Jurnal Medikora. Vol VI, No 2. November 2010 Hal: 29-36
Saydah, S., \& Lochner, K. (2010). Socioeconomic Status and Risk of Diabetes-Related Mortality in the U.S. Public Health Reports, 125(3), 377-

388. https://doi.org/10.1177/0033354 $\underline{91012500306}$

Vileikyte, L., Peyrot, M., Gonzalez, J.S. et al. (2009). Predictors of depressive symptoms in persons with diabetic peripheral neuropathy: a longitudinal study. Diabetologia 52, 1265-1273. https://doi.org/10.1007/s00125-0091363-2

Waspadji S., 2009. Buku Ajar Penyakit Dalam: Kaki Diabetes, Jilid III, Edisi 4, Jakarta: FK UI pp. 1961-62. 